\title{
Komplikasyonlu ve Komplikasyonsuz Tip 2 Diyabetik Hastalarda Antioksidanlar ve Lipid Peroksidasyon Durumu
}

\author{
Antioxidants and Lipid Peroxidation Status in Type 2 Diabetic \\ Patients with and without Complications \\ Yalçın Hacıoğlu ${ }^{1}$, Nurten Bahtiyar ${ }^{2}$ \\ ${ }^{1}$ İstanbul Eğitim ve Araştırma Hastanesi, Aile Hekimliği Kliniği, İSTANBUL \\ ${ }^{2}$ İstanbul Üniversitesi-Cerrahpaşa, Cerrahpaşa Tip Fakültesi, Biyofizik Anabilim Dal, İSTANBUL \\ Yazıssma Adresi / Correspondence: \\ Nurten Bahtiyar \\ İstanbul Üniversitesi-Cerrahpaşa, Cerrahpaşa Tip Fakültesi, Biyofizik Anabilim Dalı, İstanbul - Türkiye \\ T: +90212 4143000 E-mail : nurtenbahtiyar@hotmail.com \\ Geliş Tarihi / Received : 09.05.2019 Kabul Tarihi / Accepted : 14.10.2019 \\ Orcid : \\ Yalçın Hacıoğlu https://orcid.org/: 0000-0001-6009-3390 \\ Nurten Bahtiyar https://orcid.org/0000-0003-2420-8415 \\ ( Sakarya Tip Dergisi / Sakarya Med J 2019, 9(4):602-611 ) DOI: 10.31832/smj.562457
}

\begin{abstract}
Öz
Amaç Çalıșmamızda Tip 2 diabetes mellitus (T2DM) hastalığına bağlı vasküler komplikasyon gelișiminde malondialdehit (MDA), katalaz (KAT), süperoksit dismutaz (SOD) ve glutatyon (GSH) düzeylerinin olası değişimlerinin incelenmesi amaçlandı.

Gereç ve Çalışmaya vasküler komplikasyonu olan 35 T2DM hastası (Komp (+) T2DM grubu), vasküler komplikasyonu olmayan 35 T2DM hastası (Komp (-) T2DM grubu) ve 30 Yöntemler sağlıklı birey (Kontrol grubu) dahil edildi. Tüm bireylerin plazma MDA, KAT, SOD ve GSH düzeyleri ölçüldü.

Bulgular MDA ve KAT düzeylerinin T2DM, Komp (-) T2DM, ve Komp (+) T2DM gruplarında kontrol grubuna göre arttı̆ı̆ görüldü (tümü için p<0,001). Ayrıca Komp (+) T2DM grubunun MDA ve KAT düzeyleri, Komp (-) T2DM grubuna göre artmıș olduğu gözlemlendi ( sırasılyla ( $\mathrm{p}<0,001, \mathrm{p}=0,001)$. SOD düzeylerinin T2DM, Komp (-) T2DM, ve Komp (+) T2DM gruplarında kontrol grubuna göre, Komp (+) T2DM grubunda Komp (-) T2DM grubuna göre azaldığı görüldü (sırasıyla p $<0,001, \mathrm{p}=0,002, \mathrm{p}<0,001$ ve $\mathrm{p}=0,003)$. T2DM ve Komp (+) T2DM gruplarının kontrol grubuna göre plazma GSH değerlerinin düşük olduğu bulundu (sırasıyla $\mathrm{p}=0,011,0,004)$.

Komplikasyon gelișimine göre belirteçler arasındaki iliski incelendiğinde; Komp (+) T2DM grubunda Açlık kan sekeri (AKŞ) ile HbAlc ve MDA; HbAlc ile MDA; SOD ile KAT arasında pozitif korelasyon olduğu, AKŞ ile SOD, KAT ve GSH; HbAlc ile SOD, KAT ve GSH; MDA ile SOD ve KAT; SOD ile KAT arasında negatif bir korelasyon olduğu görüldü.

Sonuç Çalışmamızın bulguları incelediğimiz oksidatif stres belirteçlerinin T2DM patogenezinde ve vasküler komplikasyon gelişiminde yer aldığını göstermektedir. T2DM hastalı̆̆ı patogenezi ve progresyonunda oksidan seviyelerin rolünü ve ilișkili mekanizmaların belirlenmesi için ileri çalıșmalara ihtiyaç duyulmaktadır.

Anahtar Tip 2 Diabetes Mellitus; Vasküler Komplikasyon; Malondialdehit; Katalaz; Superoksit Dismutaz; Glutatyon.
\end{abstract}

Abstract

Objective The aim of this study was to investigate the possible changes in malondialdehyde (MDA), catalase (CAT), superoxide dismutase (SOD), and glutathione (GSH) levels in the development of T2DM-related vascular complications.

Materials Thirty-five T2DM patients with vascular complication (Comp (+) T2DM group), 35 T2DM patients without vascular complication (Comp (-) T2DM group), and 30 healthy subjects (Control and Methods group) were included in the study. Plasma MDA, CAT, SOD and GSH levels were measured of all individuals.

Results MDA and CAT levels were found to be increased in T2DM, Comp (-) T2DM, and Comp $(+)$ T2DM groups compared to the control group ( $p<0.001$ for all). In addition, the MDA and CAT levels of the Comp (+) T2DM group were found to be increased compared to the Comp (-) T2DM group $(p<0.001, p=0.001$, respectively). SOD levels in T2DM, Comp (-) T2DM, and Comp ( + ) T2DM groups compared to the control group, and Comp (+) T2DM group compared to Comp (-) T2DM group were decreased ( $p<0.001, p=0.002, p<0.001$, and $p=0.003$, respectively). GSH values of T2DM, and Comp (+) T2DM groups were found to be low compared to the control group $(p=0.011, p=0.004$, respectively).

When the relationship between the markers according to the complication development examined; there were the positive correlations between fasting blood glucose ( $F B G$ ) and $H b A 1 c ; F B G$ and MDA; HbAIc and MDA; SOD and CAT in the Comp (+) T2DM group. Also, there were the negative correlations in the Comp (+) T2DM group between FBG and SOD; CAT and GSH; HbAlc and SOD; CAT and GSH; MDA and SOD; MDA and CAT; SOD and CAT.

Conclusion Our findings suggest that oxidative stress markers are involved in the pathogenesis and the development of vascular complications of the T2DM. Further studies are needed to determine the role of oxidant levels and related mechanisms in the pathogenesis and progression of T2DM disease.

Key words Type 2 Diabetes Mellitus; Vascular Complication; Malondialdehyde; Catalase; Superoxide dismutase; Glutathione. 


\section{GIIRIŞ}

Tip 2 diabetes mellitus (T2DM), hiperglisemi ile karakterize olan kronik metabolik bir hastalıktır. Uluslararası Diyabet Federasyonu tarafından T2DM hasta sayısının giderek arttığını bildirmektedir. Dünya nüfusunun \% 7,7'si olan 439 milyon insanın 2030 yılına kadar diyabet hastası olacağını tahmin etmektedir. ${ }^{1}$ Son yıllarda yapılan çalışmalarda hastalığın etiyopatogenezinde genetik, çevresel ve oksidatif stres olmak üzere birçok faktörün yer aldığı gösterilmiştir. ${ }^{2,3,4}$

En diş orbitallerinde eşleşmemiş elektronu bulunan iyon veya moleküllere reaktif oksijen türleri (ROT) adı verilmektedir. Bu elektronların yüksek enerjileri ROT'u oldukça reaktif hale getirmektedir. ROT, serbest oksijen radikalleri ve non-radikal ROT olmak üzere iki gruba ayrılmaktadır. ${ }^{5}$ ROT'lar arasında süperoksit (O2-•), alkoksil (RO•), peroksil (ROO•) ve hidroksil $(\mathrm{OH} \bullet)$ radikalleri gibi oksijen radikalleri bulunmaktadır. Ayrıca hidrojen peroksit $\left(\mathrm{H}_{2} \mathrm{O}_{2}\right)$ non-radikal ROT olarak oksidatif stres oluşumunda rol almaktadır. ROT’lar fizyolojik koşullarda sürekli olarak üretilmekte ve antioksidan sistem tarafından etkin bir şekilde elimine edilmektedir. ROT üretimi hücresel savunma mekanizmalarını aştığı durumlarda, kararsız olan bu moleküller lipitler, proteinler ve DNA gibi biyolojik makromoleküllerle etkileşime girerek yapısal değişikliklere yol açmaktadır. ${ }^{5,6}$

ROT'lar, glikoz ve glikozile proteinlerin otomatik oksidasyonu ile diabetes mellitusta artış göstermektedir. ${ }^{7} \mathrm{Di}$ yabetteki oksidatif stres, poliol yolağının aktivasyonu, ileri glikasyon son ürünlerinin oluşumu, protein kinaz C’nin aktivasyonu ve ardından ROT'ların oluşumu ile ilişkilendirilmektedir. Antioksidan savunma sistemi tarafından uygun bir cevap olmadığında, oksidatif stresin artmasına, strese duyarlı hücre içi sinyal yolaklarının aktivasyonuna ve hücresel hasara neden olan gen ürünlerinin oluşumuna sebep olmaktadır. ${ }^{1}$

Bu bilgileri ışığında, literatürde oksidan/antioksidan sis- temde rol alan belirteçler ile T2DM hastalığı arasındaki ilişkiyi araştıran çok sayıda çalışmanın bulunduğunu ancak bu araştırmalarda çelişkili bulguların var olduğu görülmüştür. ${ }^{3-5, ~ 8-13} \mathrm{Bu}$ çalışmada vasküler komplikasyonlu ve komplikasyonu olmayan T2DM hastalarında plazma malondialdehit (MDA), katalaz (KAT), süperoksit dismutaz (SOD) ve glutatyon (GSH) düzeyleri değerlendirerek bu belirteçlerin T2DM hastalığında ve vasküler komplikasyon gelişimindeki olası rollerinin araştırılması amaçlanmıştır.

\section{GEREÇ ve YÖNTEMLER}

Çalışmamıza İstanbul Eğitim ve Araştırma Hastanesi Aile Hekimliği Polikliniğgine Eylül-Aralık 2018 tarih aralığında başvuran 35 komplikasyonlu ve 35 komplikasyonsuz toplam 70 T2DM'li hasta ve 30 sağlıklı birey (Kontrol grubu) dahil edildi. Hastalar vasküler komplikasyonlu (Komp (+) T2DM grubu) ve vasküler komplikasyon olmayanlar (Komp (-) T2DM grubu) olmak üzere iki gruba ayrıld1. Komlikasyonlu vakaların mikrovasküler (n:11) veya makrovasküler (n:24) komplikasyonu vardı. Tüm kat1lımcılardan bilgilendirilmiş olur formu alınarak, Helsinki Deklarasyonu kurallarına uygun olarak çalışma gerçekleştirildi. Çalışma için etik kurul onayı İstanbul Eğitim ve Araştırma Hastanesi Etik Kurulu (Tarih: 03.08.2018, Karar No:1388)'ndan alındı. Vaka-kontrol araştırması olan bu çalışmaya T2DM hastası olup başka bir hastalığı olmayan (Komp (-) T2DM grubu) ve T2DM hastalığına bağlı vasküler komplikasyon gelişen bireyler (Komp (+) T2DM grubu) dahil edildi. Tip 2 DM hasta grubu Dünya Sağlik Örgütü Kriterleri dikkate alınarak oluşturuldu. ${ }^{14}$ T2DM dışında herhangi bir kronik hastalığı (HT, otoimmün hastalıklar, kanser vb.) ve enfeksiyon hastalığı olanlar çalışmaya alınmadı. Kontrol grubuna benzer yaş aralığındaki ve herhangi bir hastalığg bulunmayan sağlıklı bireyler dahil edildi.

Kontrol grubu ve T2DM hastalarından Etilendiamin tetraasetik asit (EDTA) içeren $4 \mathrm{ml}$ venöz kan örneği alınarak 1500xg'de 10 dakika santrifüj edildi. Plazma örnekleri parametrelerin ölçümleri yapılıncaya kadar $-80^{\circ} \mathrm{C}$ de sak- 
landi.

Plazma MDA tayini Buege ve Aust'un (1978) yöntemi kullanılarak lipid peroksidasyon ürünlerinden olan MDA’nın tiyobarbütirik asit (TBA) ile reaksiyon vererek $532 \mathrm{~nm}$ dalga boyunda ölçülebilen renkli bir bileşik vermesi esasına bağlı olarak gerçekleştirildi. Sonuçlar nmol/ml olarak verildi. ${ }^{15}$

Plazma KAT aktivitesi, $\mathrm{H}_{2} \mathrm{O}_{2}$ 'nin KAT tarafından parçalanması temeline dayanan spektrofotometrik yöntem ile belirlendi. $240 \mathrm{~nm}$ dalga boyunda KAT-peroksit reaksiyonu sonucunda zamanla azalan absorbans farkı kullanılarak hesaplama yapıldı. Sonuçlar U/ml olarak belirlendi. ${ }^{16}$

Plazma SOD tayini için süperoksit üreticisi olarak kullanılan ksantin-ksantin oksidaz ile nitroblue tetrazolium'un (NBT) reaksiyonu kullanıldı. SOD aktivitesi reaksiyonun inhibisyon derecesi ile hesaplandı. Ölçümler 560nm dalga boyunda yapıldı. Sonuçlar U/ml olarak hesapland $1 .{ }^{17}$

Plazma GSH tayini için 412 nm'de maksimum absorbans gösteren TNB'yi oluşturmak için 5' 5'-Dithiobis 2-nitrobenzoik asit (DTNB) ve GSH arasındaki reaksiyon kullanıldı. Sonuçlar uM/l olarak verildi. ${ }^{18}$

\section{İstatistiksel Değerlendirme}

İstatistiksel değerlendirmeler "Statistical Package for the Social Sciences-SPSS 21.0 for Windows" paket programı kullanılarak gerçekleştirildi. Gruplar arasındaki anlaml1lıklar Student $t$ testi kullanılarak belirlendi. Sonuçlar ortalama \pm standart sapma (S.S.) olarak verildi ve $\mathrm{p}<0,05$ değerler anlamı olarak kabul edildi. Ayrıca Pearson korelasyon testi ile değişkenler arasındaki ilişki araştırıldı.

\section{BULGULAR}

Çalışma T2DM hastalarının oluşturduğu vaka grubu ve sağlıklı bireylerin oluşturduğu kontrol grubu ile gerçekleştirildi. Hasta ve kontrol gruplarına ait tüm veriler ortalama \pm standart sapma (S.S.) olarak verildi. Demografik bulgular incelendiğinde; gruplar arasında cinsiyet dağıl1mının istatistiksel olarak anlamlı bir değişim göstermediği görüldü (tümü için p>0,05). Komp (+) T2DM grubunun yaş verileri Kontrol ve Komp (-) T2DM grubuna göre artmış olduğu saptand 1 (sırasıyla $\mathrm{p}=0,001$ ve $\mathrm{p}<0,001$ ). Vücut kitle indeksi (VKI) değerleri ise T2DM, Komp (-) T2DM, Komp (+) T2DM gruplarının kontrol grubuna göre anlamlı derecede yüksek olduğu bulundu (sırasıyla $\mathrm{p}<0,001$, $\mathrm{p}=0,005$ ve $\mathrm{p}<0,001)$. Açlık kan şekeri (AKŞ) ve HbAlc değerleri T2DM, Komp (-) T2DM, Komp (+) T2DM gruplarının kontrol grubuna göre istatistiksel olarak anlamlı derecede yüksek olduğu bulundu (tümü için $\mathrm{p}<0,0001$ ). Ayrica Komp (+) T2DM grubunun AKŞ ve HbAlc değerleri Komp (-) T2DM grubuna göre yüksek olduğu görüldü (sırasıyla $\mathrm{p}=0,0002, \mathrm{p}<0,001$ ). Sistolik kan basıncı benzer şekilde değerleri T2DM, Komp (-) T2DM, Komp (+) T2DM gruplarının kontrol grubuna göre istatistiksel olarak anlamlı derecede yüksek olduğu bulundu (tümü için p<0,001). Ayrıca Komp (+) T2DM grubunun sistolik kan basıncı değerleri Komp (-) T2DM grubuna göre yüksek olduğu tespit edildi $(\mathrm{p}=0,008)$. Diyastolik kan basıncı benzer şekilde değerleri T2DM, Komp (-) T2DM, Komp (+) T2DM gruplarının kontrol grubuna göre istatistiksel olarak anlamlı derecede yüksek olduğu bulundu (sırasıyla $\mathrm{p}=0,003, \mathrm{p}<0,001, \mathrm{p}=0,032)$. Ayrıca Komp (+) T2DM grubunun diyastolik kan basıncı değerleri Komp (-) T2DM grubuna göre yüksek olduğu saptand $1(p=0,033)$ (Tablo 1$)$.

Vaka gruplarının plazma MDA düzeyleri karşılaştırıldığında; T2DM, Komp (-) T2DM, ve Komp (+) T2DM gruplarının kontrol grubuna göre MDA düzeylerinin arttığı görüldü (tümü için p<0,001). Ayrıca Komp (+) T2DM grubunun plazma MDA düzeyleri, Komp (-) T2DM grubuna göre istatistiksel olarak artmış olduğu bulundu ( $\mathrm{p}<0,001)$ (Şekil 1).

Hasta gruplarının plazma KAT düzeyleri karşılaştırıldığında; T2DM, Komp (-) T2DM, ve Komp (+) T2DM gruplarının kontrol grubuna göre KAT düzeylerinin de arttığı görüldü (tümü için p<0,001). Ayrıca Komp (+) T2DM 
Sakarya Tip Dergisi 2019;9(4):602-611

HACIOĞLU ve Ark., Tip 2 Diyabette Komplikasyon ve Oksidan Denge Durumu

\begin{tabular}{|c|c|c|c|c|}
\hline & Kontrol (n:30) & T2DM (n:70) & Komp (-) T2DM (n:35) & Komp (+) T2DM (n:35) \\
\hline Cinsiyet (E/K) & $13 / 17$ & $38 / 32$ & $16 / 19$ & $22 / 13$ \\
\hline Yaş (Yil) & $54,40 \pm 8,12$ & $56,74 \pm 1,97$ & $51,17 \pm 9,46$ & $62,31 \pm 9,31^{c^{* * x+} d^{* * *}}$ \\
\hline VKİ (kg/m2) & $26,22 \pm 2,01$ & $28,94 \pm 3,60^{\mathrm{a}^{* * *}}$ & $28,24 \pm 3,29^{b^{\star *}}$ & $29,63 \pm 3,80^{c+*+}$ \\
\hline Diyabet Süresi (Yil) & - & $3-20$ & $3-12$ & $7-20$ \\
\hline $\begin{array}{l}\text { Mikro/Makrovasküler } \\
\text { Komplikasyon }\end{array}$ & - & $11 / 24$ & - & $11 / 24$ \\
\hline AKŞ (mg/dl) & $83,07 \pm 10,53$ & $147,10 \pm 15,16^{\mathrm{a}^{* * *}}$ & $140,50 \pm 14,10^{\mathrm{b}^{* * *}}$ & $153,50 \pm 13,42^{\mathrm{c}^{* * *}, \mathrm{~d}^{+* *+}}$ \\
\hline HbAlc (\%) & $4,23 \pm 0,33$ & $7,41 \pm 1,16^{a^{* * *}}$ & $6,54 \pm 0,56^{\mathrm{b}^{\mathrm{x} *}}$ & $8,27 \pm 0,94^{\mathrm{c}^{* * * x}, \mathrm{~d}^{* * *}}$ \\
\hline $\begin{array}{l}\text { Sistolik Kan Basıncı } \\
(\mathrm{mmHg})\end{array}$ & $121,20 \pm 7,73$ & $138,50 \pm 13,94^{\mathrm{a}^{* * *}}$ & $134,10 \pm 11,60^{\mathrm{b}^{* * x}}$ & $142,90 \pm 14,87^{c+4 x, d^{* * x}}$ \\
\hline $\begin{array}{l}\text { Diyastolik Kan Basıncı } \\
(\mathrm{mmHg})\end{array}$ & $78,17 \pm 4,99$ & $83,07 \pm 8,18^{\mathrm{a}^{*+}}$ & $80,01 \pm 5,40^{b^{*}}$ & $85,14 \pm 9,89^{9^{* * * *}, \mathrm{~d}^{*}}$ \\
\hline Sigara $(-/+)$ & $30 / 0$ & $56 / 14$ & $30 / 5$ & $26 / 9$ \\
\hline Alkol (-/+) & $30 / 0$ & $63 / 7$ & $32 / 3$ & $31 / 4$ \\
\hline \multicolumn{5}{|c|}{ 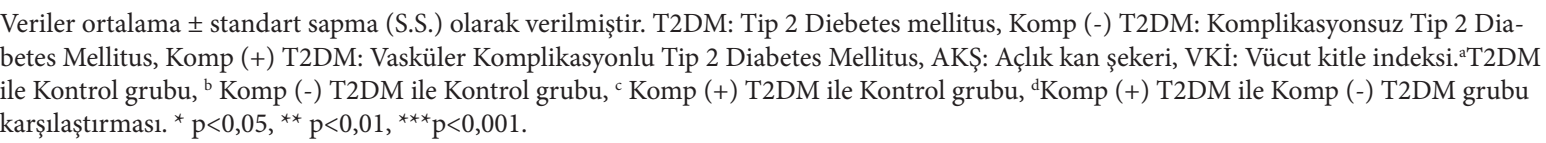 } \\
\hline
\end{tabular}

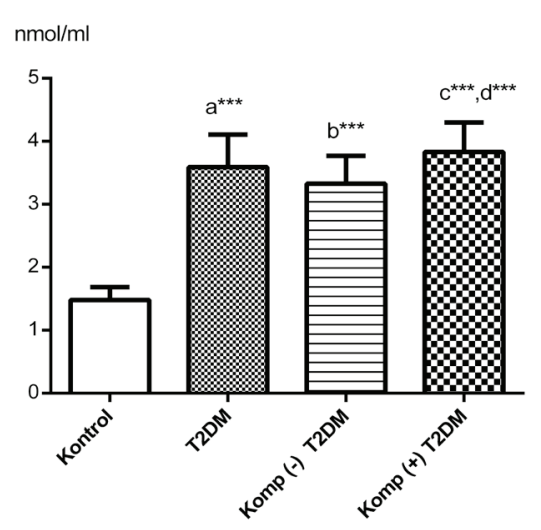

Şekil 1. Vaka ve Kontrol Gruplarına ait Plazma MDA Değerleri. T2DM: Tip 2 Diebetes mellitus, Komp (-) T2DM: Komplikasyonsuz Tip 2 Diabetes Mellitus, Komp (+) T2DM: Vasküler Komplikasyonlu Tip 2 Diabetes Mellitus. ${ }^{a}$ T2DM ile Kontrol grubu, ${ }^{b} \mathrm{Komp}$ (-) T2DM ile Kontrol grubu,

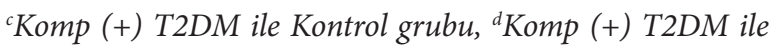
Komp (-) T2DM grubu karşılaştırması. ${ }^{*} p<0,05,{ }^{* *} p<0,01$, ${ }^{* * *} p<0,001$. grubunun plazma KAT verilerinin benzer şeklde Komp (-) T2DM grubuna göre arttğı görüldü ( $\mathrm{p}=0,001)$ (Şekil 2). Plazma SOD düzeyleri ile ilgili veriler incelendiğinde;

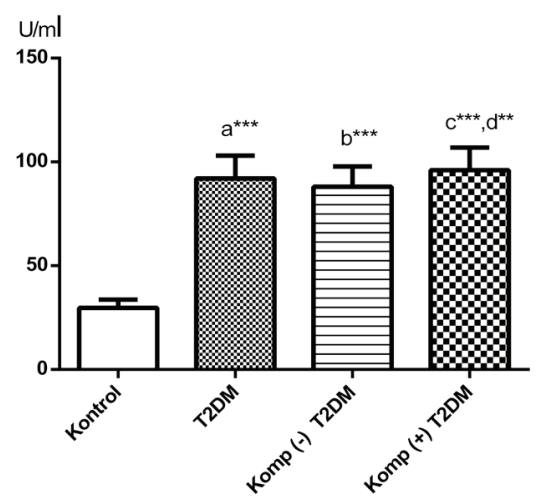

Şekil 2. Vaka ve Kontrol Gruplarina ait Plazma SOD Degerleri. T2DM: Tip 2 Diebetes mellitus, Komp (-) T2DM: Komplikasyonsuz Tip 2 Diabetes Mellitus, Komp (+) T2DM: Vasküler Komplikasyonlu Tip 2 Diabetes Mellitus. ${ }^{a}$ T2DM ile Kontrol grubu, ${ }^{b} \mathrm{Komp}(-)$ T2DM ile Kontrol grubu,

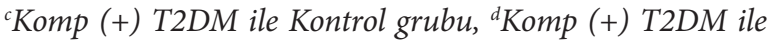
Komp (-) T2DM grubu karşılaştırması. ${ }^{*} p<0,05,{ }^{* *} p<0,01$, ${ }^{* * *} p<0,001$. 
T2DM, Komp (-) T2DM, ve Komp (+) T2DM gruplarının kontrol grubuna göre SOD değerlerinin istatistiksel olarak anlamlı derecede azaldığı görüldü (sırasıyla $\mathrm{p}<0,001$, $\mathrm{p}=0,002$ ve $\mathrm{p}<0,001)$. Ayrica Komp (+) T2DM grubunun plazma KAT düzeylerinin Komp (-) T2DM grubuna göre istatistiksel olarak anlamlı derecede azalmış olduğu saptandı $(\mathrm{p}=0,003)$ (Şekil 3).

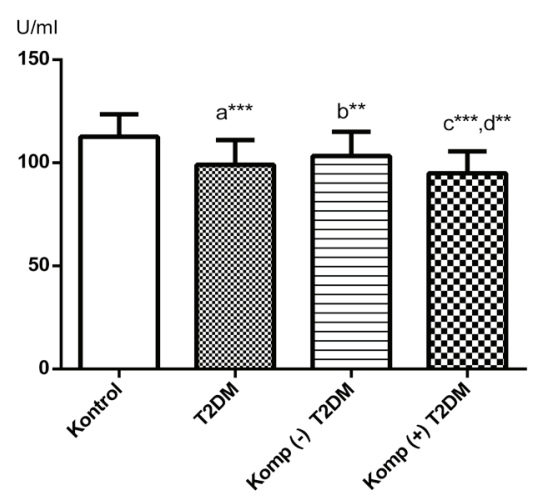

Şekil 3. Vaka ve Kontrol Gruplarına ait Plazma KAT Değerleri. T2DM: Tip 2 Diebetes mellitus, Komp (-) T2DM: Komplikasyonsuz Tip 2 Diabetes Mellitus, Komp (+) T2DM: Vasküler Komplikasyonlu Tip 2 Diabetes Mellitus. ${ }^{a} T 2 D M$ ile Kontrol grubu, ${ }^{b} \mathrm{Komp} \mathrm{(-)} \mathrm{T2DM} \mathrm{ile} \mathrm{Kontrol} \mathrm{grubu,}$ ${ }^{c} \mathrm{Komp}(+)$ T2DM ile Kontrol grubu, ${ }^{d} \mathrm{Komp}(+)$ T2DM ile Komp (-) T2DM grubu karşılaştırması. ${ }^{*} p<0,05,{ }^{* *} p<0,01$, ${ }^{* * *} p<0,001$

GSH düzeyleri ile ilgili veriler incelendiğinde; T2DM ve Komp (+) T2DM gruplarının kontrol grubuna göre plazma GSH değerlerinin istatistiksel olarak anlamlı derecede azaldığ görüldü (sırasıyla p=0,011, 0,004). Ayrıca Komp (+) T2DM ve Komp (-) T2DM grubuna göre istatistiksel anlamlılık gözlenmedi ( $\mathrm{p}>0,05)$ (Şekil 4).

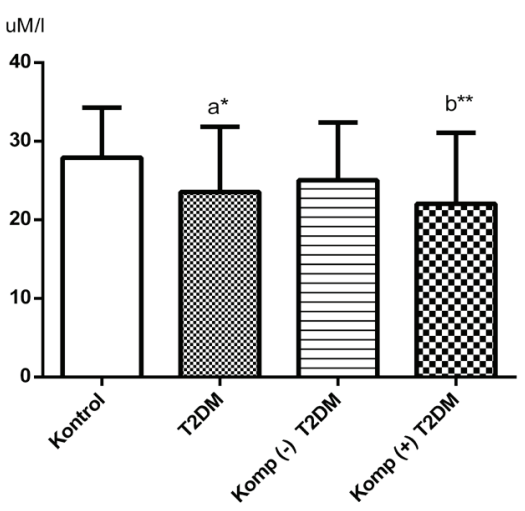

Şekil 4. Vaka ve Kontrol Gruplarına ait Plazma GSH Değerleri. T2DM: Tip 2 Diebetes mellitus, Komp (-) T2DM: Komplikasyonsuz Tip 2 Diabetes Mellitus, Komp (+) T2DM: Vasküler Komplikasyonlu Tip 2 Diabetes Mellitus. ${ }^{a}$ T2DM ile Kontrol grubu, ${ }^{b} \mathrm{Komp}(+)$ T2DM ile Kontrol grubu karşılaştırması. ${ }^{*} p<0,05,{ }^{* *} p<0,01$.

T2DM grubunda AKŞ, HbA1c, oksidan ve antioksidan belirteçler arasındaki ilişki incelendiğinde; AKŞ ile HbA1c ve MDA; MDA ile KAT; SOD ile GSH arasında pozitif korelasyon olduğu görüldü. AKŞ ile SOD ve GSH; HbA1c ile SOD ve GSH; MDA ile SOD ve GSH arasında negatif bir korelasyon olduğu gözlemlendi (Tablo 2).

\begin{tabular}{|c|c|c|c|c|c|}
\hline & AKŞ & HbAlc & MDA & SOD & KAT \\
\hline $\mathrm{HbAlc}$ & $0,638^{* * *}$ & & & & \\
\hline MDA & $0,510^{* * *}$ & $0,766^{* * *}$ & & & \\
\hline SOD & $-0,370^{*}$ & $-0,604^{* * *}$ & $-0,531^{\star * *}$ & & \\
\hline KAT & 0,208 & 0,161 & $0,267^{*}$ & $-0,132$ & \\
\hline GSH & $-0,307^{*}$ & $-0,440^{* *}$ & $-0,382^{\star *}$ & $0,327^{\star}$ & $-0,129$ \\
\hline \multicolumn{6}{|c|}{$\begin{array}{l}\text { Değerler r; korelasyon katsayısı olarak verilmiştir, AKŞ: Açlık kan şekeri, MDA: malon- } \\
\text { dialdehit, KAT: katalaz, SOD: süperoksit dismutaz, GSH: glutatyon. }{ }^{*} \mathrm{p}<0,05,{ }^{* *} \mathrm{p}<0,01 \text {, } \\
{ }^{* * *} \mathrm{p}<0,0001 \text { olarak kabul edilmiștir (Pearson korelasyonu). }\end{array}$} \\
\hline
\end{tabular}

Komp (-) T2DM grubunda belirteçler arasındaki ilişki incelendiğinde; AKŞ ile HbA1c ve MDA; HbA1c ile KAT; MDA ile KAT arasında pozitif korelasyon olduğu görüldü. HbA1c ile SOD ve GSH; MDA ile SOD ve GSH; SOD ile KAT arasında negatif bir korelasyon olduğu gözlemlendi (Tablo 3). 
Tablo 3. Komp (-) T2DM Grubuna ait Plazma AKŞ, HbA1c, MDA, SOD, KAT, GSH Düzeylerinin Korelasyonu

\begin{tabular}{|l|c|c|c|c|c|}
\hline & AKŞ & HbAlc & MDA & SOD & KAT \\
\hline HbAlc & $0,415^{*}$ & & & & \\
\hline MDA & $0,349^{*}$ & $0,805^{* * *}$ & & & \\
\hline SOD & $-0,283$ & $-0,504^{* *}$ & $-0,459^{* *}$ & & \\
\hline KAT & 0,192 & $0,690^{* * *}$ & $0,866^{* * *}$ & $-0,412^{*}$ & \\
\hline GSH & $-0,272$ & $-0,587^{* *}$ & $-0,476^{* *}$ & 0,269 & $-0,399^{*}$ \\
\hline
\end{tabular}

Değerler r; korelasyon katsayısı olarak verilmiștir, AKŞ: Açlık kan şekeri, MDA: malondialdehit, KAT: katalaz, SOD: süperoksit dismutaz, GSH: glutatyon. ${ }^{*} \mathrm{p}<0,05,{ }^{* *} \mathrm{p}<0,01,{ }^{* * *} \mathrm{p}<0,0001$ olarak kabul edilmiştir (Pearson korelasyonu).

Komp (+) T2DM grubunda araştırılan belirteçler arasındaki ilişki incelendiğinde AKŞ ile HbA1c ve MDA; HbA1c ile MDA; SOD ile KAT arasında pozitif korelasyon olduğu görüldü. AKŞ ile SOD, KAT ve GSH; HbA1c ile SOD, KAT ve GSH; MDA ile SOD ve KAT; SOD ile KAT arasında negatif bir korelasyon olduğu saptandı (Tablo 4).

Tablo 4. Komp (+) T2DM Grubuna ait Plazma AKŞ, HbA1c, MDA, SOD, KAT, GSH Düzeylerinin Korelasyonu

\begin{tabular}{|l|c|c|c|c|c|}
\hline & AKŞ & HbAlc & MDA & SOD & KAT \\
\hline HbAlc & $0,630^{* * *}$ & & & & \\
\hline MDA & $0,412^{*}$ & $0,657^{* * *}$ & & & \\
\hline SOD & $-0,457^{* *}$ & $-0,613^{* * *}$ & $-0,420^{*}$ & & \\
\hline KAT & $-0,526^{* * *}$ & $-0,648^{* * *}$ & $-0,501^{* *}$ & $0,397^{*}$ & \\
\hline GSH & $-0,250$ & $-0,418^{*}$ & $-0,245$ & 0,307 & 0,170 \\
\hline
\end{tabular}

Değerler $r$; korelasyon katsayısı olarak verilmiştir, AKŞ: Açlık kan şekeri, MDA: malondialdehit, KAT: katalaz, SOD: süperoksit dismutaz, GSH: glutatyon. ${ }^{*} \mathrm{p}<0,05,{ }^{* *} \mathrm{p}<0,01,{ }^{* * *} \mathrm{p}<0,0001$ olarak kabul edilmiştir (Pearson korelasyonu).

\section{TARTIŞMA}

T2DM'de vasküler komplikasyonlarının gelişiminde oksidatif stresin önemli rol oynadı̆̆ 1 düşünülmektedir. ${ }^{19,20}$ Diyabetle ilişkili epidemiyolojik çalışmalar mortalite ile vasküler komplikasyonlar arasında ilişki olduğunu bildirmektedir. ${ }^{19}$ Proteinlerin enzimatik olmayan glikasyonu, glukoz oksidasyonu ve artmış lipid peroksidasyonu diyabette serbest radikal oluşumu ve oksidatif strese bağlı insülin direncide artışa yol açmaktadır. ${ }^{21}$ Araştırmalara göre lipidlerin yanı sıra apo-B monomerleri arasındaki radikal kaynaklı çapraz bağlanma nedeniyle oksidatif olarak çözünmeyen agregalar oluşturan düşük yoğunluklu lipopro- tein (LDL)'in apolipoprotein bileşeni diyabetik komplikasyonlardaki oksidatif hasardan sorumludur. ${ }^{19}$

Diyabet hastalığında komplikasyonunun gelişimi ve ilerlemesinde lipitlere, proteinlere ve DNA'ya zarar verme yeteneklerinden dolayı, serbest radikallerin önemli rol oynadıkları bildirilmektedir. ${ }^{22-24}$ Plazma antioksidan ve prooksidanlar içeren önemli bir kompanenttir. Hücreyi ve hücresel biyomolekülleri oksidatif strese karşı koruyan birçok bileşik plazmada bulunmaktadır. Tüm bu moleküllerin plazmadaki birleştirilmiş etkisi plazmanın antioksidan kapasitesini temsil etmektedir. ${ }^{25}$

Bu çalışmamızda, T2DM hastalığına bağlı vaküler komplikasyon gelişimindeki olası rolünü incelemek üzere oksidatif stres belirteci olarak plazma MDA seçilmiştir. Ayrıca, plazma KAT, SOD ve GSH enzim aktiviteleri oksidan savunma sisteminin belirteçleri olarak ele alınmıştır.

MDA, serbest radikallerin oluşturduğu lipit oksidasyonundan elde edilen oldukça toksik bir yan üründür. MDA geri dönüşümlü ve geri dönüşümsüz olarak proteinler ve fosfolipidlerle reaksiyona girmektedir. Özellikle kardiyovasküler sistemdeki kollajen, MDA’nın aracılık ettiği çapraz bağlar ile sertleşmekte ve yeniden yapılanmaya karşı dirençli hale gelmektedir. Diabetes mellitus'ta kollajenin şeker katkılı maddeler tarafından gerçekleştirilen modifikasyonu, bir dizi glikasyon ürününü oluşturmaktadır. Bu glikasyon ürününleri daha sonra lipidlerin MDA'ya parçalanmasını uyarmakta ve dolayısıyla daha önce modifiye edilmiş kollajenin MDA ile daha fazla çapraz bağ oluşturmasına sebep olmaktadır. Temel amino asit yan zincirlerinin MDA modifikasyonu, molekülün yük profilinde modifiye hücre-matris etkileşimleri ile sonuçlanan değişikliğe neden olmaktadır. ${ }^{26}$

T2DM hastalığında MDA olası değişimi ile ilgili yaptığımız literatür araştırmasında diyabetik olgularda MDA düzeyinde bir artışın olduğu görülmektedir. ${ }^{12,27}$ Kötü glisemik kontrollü T2DM hastalarında iyi glisemik kontollü 
olan hastalara göre serum MDA düzeyinde bir artış olduğu bildirilmektedir. ${ }^{28}$ Ayrıca diyabetik hastalarda yüksek MDA düzeylerinin mikrovasküler ve makrovasküler komplikasyon riski ile ilişkili olduğunu gösteren çalışmalar bulunmaktadır. ${ }^{3-4,29}$ Marhoffer ve ark. uzun süreli kötü kontrol edilen T2DM'de MDA artışının diyabetik retinopatiye neden olabileceğini bildirmişlerdir. ${ }^{29}$ Rodriguez-Carrizalez ve ark. ise lipid peroksidasyon ürünlerinin, retinopatinin ciddiyeti ile birlikte giderek arttığını ifade etmektedir. ${ }^{30}$ Çalışmamızın verileri incelendiğinde T2DM grubunda kontrol grubuna göre plazma MDA düzeylerinde anlamlı bir artış olduğu olduğu görülmektedir. Ayrıca vasküler komplikasyonlu T2DM grubunda plazma MDA düzeylerinin komplikasyonsuz T2DM grubuna göre arttığ glikasyonundan dolayı lipid peroksitlerinin artmış olabileceğini göstermektedir. ${ }^{30}$ Artan lipit peroksit seviyeleri oksidatif hasara, membran proteinlerinde ve lipidlerinde çapraz bağlanmaya neden olabilir. ${ }^{12}$

KAT, çoğu canlıda bulunan antioksidan bir enzimdir. Diyabet ve kardiyovasküler hastalıklar gibi oksidatif stres kaynaklı komplikasyonlara karşı önemli rolü bulunmaktadır. KAT, $\mathrm{H}_{2} \mathrm{O}_{2}$ metabolizmasının ana düzenleyicisi olarak görev almaktadır. $\mathrm{H}_{2} \mathrm{O}_{2}$ oldukça reaktif bir moleküldür ve enerji metabolizmasının doğal yan ürünü olarak oluşmaktadır. $\mathrm{H}_{2} \mathrm{O}_{2}$ 'nin konsantrasyonundaki artış proteinlerde, DNA'da, RNA'da ve lipidlerde önemli hasarlara neden olmaktadır. KAT, enzimatik olarak $\mathrm{H}_{2} \mathrm{O}_{2}$ 'yi oksijene ve suya dönüştürerek nötralize etmektedir. KAT eksikliği olan hastalarda artan diyabet riski olduğu bildirilmiştir. Bu enzimin eksikliği, Beta hücresinde oksidatif stresin artmasına ve hücre tipinin bozulmasına neden olmaktadır. Beta hücreleri mitokondri bakımından zengindir ve bu nedenle ROT kaynağı olabilir. KAT, pankreas beta hücrelerini $\mathrm{H}_{2} \mathrm{O}_{2}$ 'nin sebep olduğu zararlardan korumaktadır. ${ }^{31,32}$

Yapılan çalışmalarda diyabetik hastalarda antioksidan enzimlerin sonuçları ile ilişkili çelişkili veriler bulunmaktadır. ${ }^{8,9,11}$ T2DM hastalığında KAT aktivitesi ile ilgili yapılan araştırmalar incelendiğinde Sözmen ve ark. T2DM hastalarında KAT aktivitesinde kontrol grubuna göre üç kat arttığını, Atli ve ark. da benzer şekilde KAT düzeylerinin T2DM hastalarında kontrol grubuna göre arttığını, ayrıca kamplikasyonlu T2DM hastalarında bu düzeyin daha da yüksek olduğunu bildirmişlerdir., ${ }^{8,11}$ Jandric-Balen ve ark. ise serum KAT aktivitesinin diyabetik hastalarda kontrol grubuna göre azaldığını bildirmişlerdir. ${ }^{9}$ Çalışmamızın verileri incelendiğinde T2DM grubunda kontrol grubuna göre plazma KAT düzeylerinde anlamlı bir artış olduğu görülmektedir. Ayrıca vasküler komplikasyonlu T2DM grubunda plazma KAT düzeylerinin komplikasyonsuz T2DM grubuna göre artmış olduğu saptandı. Verilerimiz, diyabetik hastalarda peroksit radikal artışının KAT aktivitesinin artmasına sebep olabilir görüşünü desteklemektedir. ${ }^{4}$

SOD, süperoksit anyonunun $\left(\mathrm{O}_{2} \cdot-\right), \mathrm{H}_{2} \mathrm{O}_{2}$ ve oksijene $\left(\mathrm{O}_{2}\right)$ ayrışmasını katalize eden antioksidan bir enzimdir. SOD, ROT tarafından üretilen hücresel ve histolojik hasarlara karşı koruyucu rol oynamaktadır. ${ }^{32,33}$

T2DM hastalığında SOD aktivitesi ile ilgili yapılan araştırmalar incelendiğinde Jandric-Balen ve ark. antioksidan enzimlerden SOD düzeyinin T2DM'de sağlıklı kontrol grubuna göre anlamlı olarak arttığını, Hisalkar ve ark. ve Sailaja ve ark. T2DM hastalarında kontrollere kıyasla belirgin şekilde azaldığını, Sözmen ve ark., Kesavlu ve ark. ve Atli ve ark. T2DM hastaların SOD aktivitelerinde herhangi bir değişiklik gözlemlemediklerini bildirmişlerdir. ${ }^{4,8-11,27}$ Srivatsan ve ark. komplikasyonsuz T2DM'de SOD düzeyinin artığını ancak komplikasyonlu T2DM'de azaldığını bildirmişlerdir. ${ }^{34}$ Kesavulu ve ark. benzer şekilde SOD aktivitesi, mikrovasküler komplikasyonlu diyabetik hastalarda komplikasyonsuz olanlara göre önemli ölçüde azaldığını gözlemişlerdir. ${ }^{4}$

Çalışmamızın verileri incelendiğinde T2DM grubunda kontrol grubuna göre plazma SOD düzeylerinde anlamlı bir azalma olduğu görülmektedir. Ayrıca vasküler komplikasyonlu T2DM grubunda plazma SOD düzeylerinin 
komplikasyonu olmayan T2DM grubuna göre azalmış olduğu dikkati çekmektedir. Bulgularımız, komplikasyonlu T2DM hastalığında oluşan aşırı oksidatif strese bağlı SOD düzeylerinde önemli bir düşüş olduğunu ortaya koymaktadır. SOD düzeylerindeki bu düşüş sadece O2-•'de bir artışa değil, aynı zamanda diğer ROT yükselmesine ve diyabette lipid peroksidasyon işlemlerinin yoğunlaşmasına neden olabilir. ${ }^{10}$

Glutatyon (GSH), intraselüler konsantrasyonu yüksek olan Beta-Lglutamil-L-sisteinilglisin'den oluşan bir tripeptittir. GSH hücrelerde bulunan bir antioksidandır ve ayrıca hücresel düzeyde redoks dengesizliğinin biyobelirteci olarak kabul edilmektedir. GSH'in yabancı radikalleri detoksifiye edebildiği, çeşitli enzimatik reaksiyonlarda koenzim görevi görebildiği, doku hasarını önleyebildiği bildirilmektedir. T2DM'de olası GSH değişimini incelemek üzere yaptığımız literatür araştırmamızda çalışmaların genellikle hastalığın azalmış GSH düzeyi ile ilişkilendirildiği görülmüştür. Upadhya ve ark. eritrosit, Mendez ve ark. plazma, ve Aouacheri ve ark. ise serum GSH düzeylerinin T2DM grubunda kontrole göre azaldığını bildirmişlerdir. ${ }^{12,35,36}$ T2DM'de komplikasyon gelişimi ve GSH düzeyi değişiminin incelendiği çalışmalarda ise çelişkili bulgular dikkati çekmiştir. Sundaram ve ark. komplikasyonlu ve komplikasyonsuz T2DM hastalarında tam kan GSH düzeyinin kontrole göre azaldığını, Memisogullari ve ark. komplikasyonlu ve komplikasyonsuz T2DM hastalarında eritrosit GSH düzeyinin kontrole göre azaldığın1, ancak Srivatsan ve ark. komplikasyonsuz T2DM hastalarında kontrole göre eritrosit GSH düzeyinde anlamlı bir azalma olduğunu, komplikasyonlu diyabette anlamlı bir değişimin olmadığını, Bhatia ve ark. ise nefropati gelişen T2DM hastalarında serum GSH düzeyinin azaldığ ${ }^{-}$ n1, komplikasyonsuz hastalarda kontrole göre anlamlı bir değişim olmadığını bildirmişlerdir. ${ }^{6,7,33,34}$ Çalışmamızın verileri incelendiğinde T2DM grubunda kontrol grubuna göre plazma GSH düzeylerinde anlamlı bir azalma olduğu görülmektedir. Komplikasyonsuz T2DM grubu ile kontrol grubu kıyaslamasında anlamlı bir değişim bulunmamakta, ancak vasküler komplikasyonlu T2DM grubunda plazma GSH düzeylerinin kontrol grubuna göre azalmış olduğu dikkati çekmektedir. Plazmanın düşük GSH içeriği, hücrelerin gelişmiş pro-oksidan ortamını yansıtmaktadır. Azalmış plazma GSH düzeyi T2DM hastalarında oksidatif stresle mücadele için antioksidanların telafi edici bir mekanizmasından kaynaklanabilir.

Serbest radikallerin yaşlanma sürecindeki rolleri ile ilgili görüşler uzun zamandır yaşlanmanın serbest radikal teorisi ile öne sürülmektedir. ${ }^{37} \mathrm{Bu}$ teori, savunma mekanizmalarının serbest radikal hasarına yanıt verememesinin sonucunda yaşlanmanın geliştiğini speküle etmektedir. ${ }^{38}$ Ancak yapılan bazı çalışmalar oksidatif stresin diyabet, demans, vasküler hastalıklar, osteoporoz gibi yaşın artışı ile görülen hastalıkların gelişiminde önemli bir rolü olduğu bildirilmektedir. ${ }^{37,39}$

Çalışma gruplarımızda yaş dağılımı ile ilgili bulguları incelendiğinde tüm hastaları içeren T2DM grubu ve Komp (-) T2DM ile kontrol grubu arasında anamlı bir değişim olmadığı (sırasıyla p=0,296, p=0,149), ancak Komp $(+)$ T2DM grubunun Kontrol grubuna göre artmış olduğu dikkati çekmektedir ( $\mathrm{p}=0,001)$. Çalışmamızda yaş ve incelediğimiz tüm oksidatif stres belirteçleri arasındaki ilişkiyi belirlemek üzere yapılan korelasyon çalışmasında ise anlamlı bir değişim görülmemiştir. Yaşla ilgili elde ettiğimiz bu değişimin sebebi diyabet hastalarında vasküler komplikasyon gelişiminin hastalığın geç evrelerinde ortaya çıkması ve uzun süreli hipergliseminin en önemli sonucu olduğu görüşünü desteklemektedir. ${ }^{2}$ T2DM hastalığında glikasyon ile oksidatif stres belirteçleri arasındaki ilişkiyi belirlemek üzere yapılan korelasyon çalışmasında glikasyon artışı sonucunda oksidan ve antioksidan belirteçlerin değişim gösterdiği, komplikasyon gelişen grupta ilişkili olan belirteçlerin sayısının arttığı dikkati çekmektedir.

Sonuç olarak çalışmamızın bulguları T2DM hastalarında plazma MDA ve KAT düzeylerinin arttığını, SOD ve GSH düzeylerinin azaldığını, vasküler komplikasyon gelişimi ile 
bu değerlerdeki artış ve azalmanın daha belirgin hale gel-

diğini göstermektedir. Bu bulgular bozulmuş antioksidan metabolizmanın T2DM patogenezinde ve progresyonunda rol oynayabileceği fikrini akla getirmektedir. Daha ileri çalışmalar ile bu mekanizmaların araştırılmasına ihtiyaç duyulmaktadır.

\section{Çıkar ilişsisi}

Yazarların herhangi bir çıkar dayalı bir ilişkisi bulunmamaktadır. 
Sakarya Tip Dergisi 2019;9(4):602-611

HACIOĞLU ve Ark., Tip 2 Diyabette Komplikasyon ve Oksidan Denge Durumu

\section{Kaynaklar}

1. Zemestani $M$, Rafraf $M$, Asghari-Jafarabadi $M$. Chamomile tea improves glycemic indices and antioxidants status in patients with type 2 diabetes mellitus. Nutrition 2016; 32(1): 66-72.

2. Soumya D, Srilatha B. Late Stage Complications of Diabetes and Insulin Resistance. J Diabetes Metab. 2011; 2:167.

3. Kesavulu M, Rao BK, Giri R, Vijaya J, Subramanyam G, Apparao C. Lipid peroxidation and antioxidant enzyme status in Type 2 diabetics with coronary heart disease. Diabetes research and clinical practice 2001; 53(1): 33-39.

4. Kesavulu M, Giri R, Rao BK, Apparao C. Lipid peroxidation and antioxidant enzyme levels in type 2 diabetics with microvascular complications. 2000.

5. Çiftçi N. Oksidatif Stresin Kanserdeki Rolü: Antioksidanlar Kanser Progresyonunun Yakiti Olabilir Mi? Ahi Evran Tip Dergisi 2017; 1(1): 8-13.

6. Bhatia S, Shukla R, Madhu SV, Gambhir JK, Prabhu KM. Antioxidant status, lipid peroxidation and nitric oxide end products in patients of type 2 diabetes mellitus with nephropathy. Clinical biochemistry 2003; 36(7): 557-562.

7. Sundaram RK, Bhaskar A, Vijayalingam S, Viswanathan M, Mohan R, Shanmugasundaram KR. Antioxidant status and lipid peroxidation in type II diabetes mellitus with and without complications. Clinical Science 1996; 90(4): 255-260.

8. Sözmen EY, Sözmen B, Delen Y, Onat T. Catalase/superoxide dismutase (SOD) and catalase/paraoxonase (PON) ratios may implicate poor glycemic control. Archives of medical research 2001; 32(4): 283-287.

9. Jandrić-Balen $M$, Božikov V, Božikov J, Metelko Ž, Jandrić I, Romić Ž. Impact of glycemic control on antioxidant enzyme activity in patients with type 2 diabetes mellitus. Diabetologia croatica 2004; 33(4): 131.

10. Hisalkar P, Patne A, Fawade M, Karnik A. Evaluation of plasma superoxide dismutase and glutathione peroxidase in type 2 diabetic patients. Biology and medicine 2012; 4(2): 65 .

11. Atli T, Keven K, Avci A, Kutlay S, Turkcapar N, Varli $M$ et al. Oxidative stress and antioxidant status in elderly diabetes mellitus and glucose intolerance patients. Archives of gerontology and geriatrics 2004; 39(3): 269-275.

12. Mendez MM, Folgado J, Tormo C, Artero A, Ascaso M, Martinez-Hervás S et al. Altered glutathione system is associated with the presence of distal symmetric peripheral polyneuropathy in type 2 diabetic subjects. Journal of Diabetes and its Complications 2015; 29(7): 923-927.

13. Memısoğullari R, Taysı S, Bakan E, Capoglu I. Antioxidant status and lipid peroxidation in type II diabetes mellitus. Cell Biochemistry and Function: Cellular biochemistry and its modulation by active agents or disease 2003; 21(3): 291-296.

14. Association AD. 2. Classification and diagnosis of diabetes: standards of medical care in diabetes-2018. Diabetes care 2018; 41(Supplement 1): S13-S27.

15. Buege J, Aust S. Microsomal lipid peroxidation Methods Enzymol 52: 302-310. Find this article online 1978.

16. Beers RF, Sizer IW. A spectrophotometric method for measuring the breakdown of hydrogen peroxide by catalase. J Biol chem 1952; 195(1): 133-140.

17. Sun Y, Oberley LW, Li Y. A simple method for clinical assay of superoxide dismutase. Clinical chemistry 1988; 34(3): 497-500.

18. Beutler E. Improved method for the determination of blood glutathione. J. lab. clin. Med. 1963; 61: 882-888.

19. Pham-Huy LA, He H, Pham-Huy C. Free radicals, antioxidants in disease and health. International journal of biomedical science: IJBS 2008; 4(2): 89.

20. Lipinski B. Pathophysiology of oxidative stress in diabetes mellitus. Journal of Diabetes and its Complications 2001; 15(4): 203-210.
21. Maritim A, Sanders a, Watkins Iii J. Diabetes, oxidative stress, and antioxidants: a review. Journal of biochemical and molecular toxicology 2003; 17(1): 24-38.

22. Moussa S. Oxidative stress in diabetes mellitus. Romanian J biophys 2008; 18(3): 225-236.

23. Ayepola OR, Brooks NL, Oguntibeju OO. Oxidative stress and diabetic complications: the role of antioxidant vitamins and flavonoids. In: Antioxidant-Antidiabetic Agents and $\mathrm{Hu}$ man Health. IntechOpen, 2014.

24. Asmat U, Abad K, Ismail K. Diabetes mellitus and oxidative stress-a concise review. Saudi Pharmaceutical Journal 2016; 24(5): 547-553.

25. Khan AN, Khan RA, Ahmad M, Mushtaq N. Role of antioxidant in oxidative stress and diabetes mellitus. Journal of pharmacognosy and phytochemistry 2015; 3(6): 217-220.

26. Slatter D, Bolton C, Bailey A. The importance of lipid-derived malondialdehyde in diabetes mellitus. Diabetologia 2000; 43(5): 550-557.

27. Sailaja Y, Baskar R, Saralakumari D. The antioxidant status during maturation of reticulocytes to erythrocytes in type 2 diabetics. Free Radical Biology and Medicine 2003; 35(2): 133-139.

28. Fatani SH, Babakr AT, NourEldin EM, Almarzouki AA. Lipid peroxidation is associated with poor control of type-2 diabetes mellitus. Diabetes \& Metabolic Syndrome: Clinical Research \& Reviews 2016; 10(2): S64-S67.

29. Marhoffer W, Stein M, Maeser E, Federlin K. Impairment of polymorphonuclear leukocyte function and metabolic control of diabetes. Diabetes care 1992; 15(2): 256-260.

30. Rodríguez-Carrizalez AD, Castellanos-González JA, Martínez-Romero EC, Miller-Arrevillaga $G$, Villa-Hernández D, Hernández-Godínez PP et al. Oxidants, antioxidants and mitochondrial function in non-proliferative diabetic retinopathy. Journal of diabetes 2014; 6(2): 167-175.

31. Takemoto $K$, Tanaka $M$, Iwata $H$, Nishihara $R$, Ishihara $K$, Wang D-H et al. Low catalase activity in blood is associated with the diabetes caused by alloxan. Clinica Chimica Acta 2009; 407(1-2): 43-46.

32. Tiwari BK, Pandey KB, Abidi A, Rizvi SI. Markers of oxidative stress during diabetes mellitus. Journal of biomarkers 2013; 2013.

33. Beyer W, Imlay J, Fridovich I. Superoxide dismutases. In: Progress in nucleic acid research and molecular biology, vol. 40. Elsevier, 1991, pp 221-253.

34. Srivatsan R, Das S, Gadde R, Manoj-Kumar K, Taduri S, Rao N, Ramesh B, Baharani A, Shah K, Kamireddy SC, Priyatham G, Balakumaran TA, Balakumaran SS, Kamath A, Rao A. Antioxidants and lipid peroxidation status in diabetic patients with and without complications. Arch Iran Med. 2009;12(2):121-127.

35. Upadhya S, Shanbhag KK, Suneetha G, Balachandra Naidu M, Upadhya S. A study of hypoglycemic and antioxidant activity of Aegle marmelos in alloxan induced diabetic rats. Indian J Physiol Pharmacol 2004; 48(4): 476-480.

36. Aouacheri O, Saka S, Krim M, Messaadia A, Maidi I. The investigation of the oxidative stress-related parameters in type 2 diabetes mellitus. Canadian journal of diabetes 2015; 39(1): 44-49.

37. Tan BL, Norhaizan ME, Liew WP, Sulaiman Rahman H. Antioxidant and Oxidative Stress: A Mutual Interplay in Age-Related Diseases. Front Pharmacol. 2018; 16; 9:1162.

38. Islam MT. Oxidative stress and mitochondrial dysfunction-linked neurodegenerative disorders. Neurol Res. 2017;39(1):73-82.

39. Liu Z, Zhou T, Ziegler AC, Dimitrion P, and Zuo L. Oxidative stress in neurodegenerative diseases: from molecular mechanisms to clinical applications. Oxid Med Cell Longev. 2017;2017:2525967. 